\title{
Simultaneous Determination of Monoatomic Ions via Infrared Attenuated Total Reflection Spectroscopy in Aqueous Solution at Different Temperatures
}

0 (0) $1-14$

(C) The Author(s) 2016

Reprints and permissions:

sagepub.co.uk/journalsPermissions.nav DOI: 10.1 I77/0003702816652320

asp.sagepub.com

(SAGE

\author{
Florian Rauh and Boris Mizaikoff
}

\begin{abstract}
In this study, monoatomic and thus IR-inactive ions were determined via infrared attenuated total reflection (IR-ATR) spectroscopy including $\mathrm{Cl}^{-}, \mathrm{Na}^{+}, \mathrm{Mg}^{2+}, \mathrm{Ca}^{2+}, \mathrm{K}^{+}$and $\mathrm{Br}^{-}$, next to the IR-active ion $\mathrm{SO}_{4}^{2-}$. The determination of IRinactive ions is enabled, as each ion influences the infrared spectrum of bulk water by organizing the water molecules within the solvation shell around the ionic species in a unique way. Furthermore, the influence of temperature was taken into account for the potential application of this analytical technique in real-world scenarios. Using chemometric data analysis, seven ions could be discriminated at temperatures ranging between $3^{\circ} \mathrm{C}$ and $45^{\circ} \mathrm{C}$. Finally, within a sample of seawater, $\mathrm{Cl}^{-}, \mathrm{Na}^{+}, \mathrm{Mg}^{2+}$ and $\mathrm{SO}_{4}^{2-}$ could be simultaneously quantified, while the concentrations of $\mathrm{Ca}^{2+}, \mathrm{K}^{+}$and $\mathrm{Br}^{-}$ remained below the achievable limits of detection.
\end{abstract}

\section{Keywords}

Infrared spectroscopy, infrared, IR, seawater analysis, attenuated total reflection, attenuated total reflection spectroscopy, ATR, principal component analysis/regression, principal components analysis, principal components regression, PCA/PCR, chemometrics, hydration, salt ions

Date received: 9 September 2015; accepted: 29 December 2015

\section{Introduction}

Salinity is a major parameter in water analysis. Especially in marine environments, salinity is an indicator for the mixing ratio of fresh water and salt water, for boundaries between water layers, and for the location of oceanic currents. Furthermore, salinity influences the nature and composition of marine ecosystems, and is a crucial prerequisite for their existence. Conventionally, salinity is obtained as a sum parameter of all dissolved ions, as determined via measurements of density or electrical conductivity.' Yet, the origin and composition of salt in seawater is a matter of great interest since ancient times. Even Greek philosophers had speculated where the salty taste of marine waters originates, and started to perform associated scientific experiments. ${ }^{2-4}$ However, only in 1772 Lavoisier was the first to identify the major constituents of sea salt. ${ }^{5}$ A comprehensive overview on the structure of water, hydration of ions and fundamentals of infrared spectroscopy of water was published by Luck in 1974. ${ }^{6}$ Additional detailed information on the interactions of water in ionic and nonionic hydrates has been published by Kleeberg in
1987. ${ }^{7}$ Hirschfeld pointed out that near-infrared (NIR) spectroscopy may be applied for salinity measurements without sample preparation, while also enabling remote measurements. ${ }^{8}$ Lin et al. ${ }^{9}$ dissolved 7I different electrolytes in water and collected near-infrared spectra of each solution in order to develop a spectral library for the identification of dissolved ions in water. Thus, most electrolytes were identified via principal components regression analysis evaluating the changes induced in the NIR spectra of water upon addition of salts. Difference spectra and multivariate calibration models were used by Heise and Bittner for NIR spectrometric biotic fluid assays with the aim of developing a noninvasive glucose sensor. ${ }^{10}$ Steen et al. identified and quantified 16 inorganic electrolytes in aqueous solution via NIR differential absorbance spectroscopy. Using Gaussian

Institute of Analytical and Bioanalytical Chemistry, University of Ulm, Germany

\footnotetext{
Corresponding author:

Boris Mizaikoff, Institute of Analytical and Bioanalytical Chemistry, University of Ulm, Ulm, Germany.

Email: boris.mizaikoff@uni-ulm.de
} 
curve fitting, so-called truth tables were established enabling the development of miniaturized and cheap sensors for dissolved ions. "In the present study and in continuation of previous work by our research team these concepts were transferred to the mid-infrared regime for sensing dissolved ions. ${ }^{12}$

While initially appearing counterintuitive, infrared attenuated total reflection spectroscopy (IR-ATR) in the midinfrared 3-12 $\mu \mathrm{m}$ spectral regime enables the simultaneous determination and quantification of the seven most prevalent ions in seawater, with the exception of $\mathrm{SO}_{4}^{2-}$, despite their IR-inactivity, which are in order of descending concentration: $\mathrm{Cl}^{-}, \mathrm{Na}^{+}, \mathrm{Mg}^{2+}, \mathrm{SO}_{4}^{2-}, \mathrm{Ca}^{2+}, \mathrm{K}^{+}$and $\mathrm{Br}^{-}$.

A fundamental limitation of mid-infrared (MIR) spectroscopy is the high absorptivity of water. Using IR-ATR spectroscopy, this problem is resolved, as the exponentially decaying evanescent field probes only a minute sample volume adjacent to a waveguide surface. Next to this major advantage compared to other IR techniques, IRATR spectroscopy and sensors are considered to be rapidly responding and robust analytical devices enabling the simultaneous detection and quantification of several species during a single measurement given the inherent selectivity of molecular vibrations. Based on compact Fourier transform infrared (FTIR) spectrometers, this analytical technique offers in situ capabilities in a wide range of measurement scenarios. ${ }^{13-15}$

In the present study, the concept of IR-ATR spectroscopy was applied, not only to probe IR-active species such as $\mathrm{SO}_{4}^{2-}$, but also to IR-inactive monoatomic ions including $\mathrm{Cl}^{-}, \mathrm{Na}^{+}, \mathrm{Mg}^{2+}, \mathrm{Ca}^{2+}, \mathrm{K}^{+}$and $\mathrm{Br}^{-}$by analyzing their influence on the vibrational spectrum of bulk water. In aqueous solution, each ion is surrounded by a hydration shell, and therefore influences the local structure and organization of water molecules and, consequently, the molecular vibrational spectrum of $\mathrm{H}_{2} \mathrm{O}$ in a unique way. ${ }^{12,16-19}$ The dominant interaction forces between water molecules and dissolved constituents are short-range chemical interactions. Cations interact with the spare outer electrons of the water oxygen atom, while anions form hydrogen bonds with the corresponding hydrogen atoms. Longrange forces are considered weak compared to the water-water hydrogen bonds. ${ }^{20}$ In addition, spectroscopic evidence for clathrate-like hydration of several ions was found by Cooper et al. ${ }^{21}$ Correspondingly, several publications have reported the structure, thermodynamic properties and spectroscopic features of single ion-solvent clusters, ${ }^{22-26}$ but also of ion pairs solvated inside clusters of water molecules. ${ }^{18,27-31}$

In order to simultaneously determine the concentration of seven ions in aqueous solution, a multivariate calibration and data evaluation routine based on principal components analysis (PCA) was applied. Principal components are eigenvectors fitted to a $p$-dimensional data space via orthogonal transformation with $p$ being the number of independent variables, i.e., here, the wavenumbers reported in the IR spectrum. $N$ data points in this $p$-dimensional space represent the data space. The first principal component is the eigenvector fitted to the data points representing maximum variance. The second principal component represents the second largest variance within the dataset, and is orthogonal to the first one, and so on. Principal components analysis may thus be considered to be a low-dimensional projection of high-dimensional data space, as reported first by Pearson in 1901. ${ }^{32}$

Based on PCA, principal components regression (PCR) may then be used to predict the concentration of multiple analytes (here, ions) in aqueous matrices such as seawater. For this purpose, principal components are used as regressors in lieu of the wavenumber and absorbance value enabling the discrimination of highly collinear variables. Since the spectral differences induced within the spectrum of liquid water by the presence of ions are rather small, PCR appears as a highly suitable multivariate data treatment strategy solving this analytical problem. ${ }^{33-38}$

Using IR-ATR spectroscopy combined with PCA/PCRbased multivariate statistics enabled the simultaneous quantification of several ions in artificial salt solutions as well as in a real seawater sample from the Atlantic Ocean.

\section{Experimental}

For the multivariate analysis, a set of calibration solutions is prepared and measured. A PCR model is established with this data. In order to test if the model works, a so-called test set or validation set of solutions (containing different analyte concentrations than the calibration set) is prepared, measured and loaded into the model. The model is than applied to these datasets and the results are plotted with the calibration plot.

\section{Chemicals}

The chemicals sodium chloride $(\mathrm{NaCl})$, sodium bromide $(\mathrm{NaBr})$, potassium bromide $(\mathrm{KBr})$ (each $A C S$ reagent grade), potassium chloride ( $\mathrm{KCl}$, pro analysis grade), magnesium chloride hexahydrate $\left(\mathrm{MgCl}_{2} * 6 \mathrm{H}_{2} \mathrm{O}\right)$ and calcium chloride dihydrate $\left(\mathrm{CaCl}_{2} * 2 \mathrm{H}_{2} \mathrm{O}\right)$, both Ultra Grade, were purchased from Sigma-Aldrich (St. Louis, MO). Pro analysis grade $\mathrm{Na}_{2} \mathrm{SO}_{4} * 1 \mathrm{OH}_{2} \mathrm{O}$ was obtained from Merck (Darmstadt, Germany). Original seawater from the Atlantic Ocean was purchased from Rebie (Bielefeld, Germany).

In this study, one calibration/validation set was prepared containing each salt at concentrations from $0.2-4 \%(\mathrm{w} / \mathrm{v})$ except $\mathrm{Na}_{2} \mathrm{SO}_{4}$, which was added at concentrations of $0.03-0.15 \%(\mathrm{w} / \mathrm{v})$, as the sulfate anion is IR-active and thus detectable at much lower concentrations compared to monoatomic ions. In addition, the precipitation of gypsum was prevented by the rather low sulfate concentrations. 
This calibration/validation sample set was used to test if the multivariate model is able to discriminate between ions, and quantify these species. In contrast to a previous study by our research team, ${ }^{12}$ for the first time the effect of temperature was taken into account.

A second calibration/validation sample set was prepared containing ion concentrations adjusted to their presence in real-world seawater, and was then used to apply the model to an Atlantic Ocean seawater sample for quantification of the contained ions.

All solutions were prepared by subsequently mixing concentrated solutions of each salt at different ratios, and dilution with de-ionized water to a predetermined volume. In the first set of experiments, the concentration of $\mathrm{Na}_{2} \mathrm{SO}_{4}$ was kept low in order to not exceed the solubility product of gypsum, which would otherwise precipitate. Within the calibration/validation solutions for the analysis of seawater, the concentration of $\mathrm{Ca}^{2+}$ was sufficiently low to avoid precipitation. The concentration variations within the mixtures were prepared according to Brereton. ${ }^{39}$ Table SI in the Supplemental Information shows the resulting concentrations [mol/L] of each ion in each of the calibration and validation samples for the simultaneous determination and quantification of seven ions, introducing temperature as an additional variable. Furthermore, aliquots of these solutions were diluted by a factor of four and then analyzed in order to obtain an extended overall concentration range.

For the determination of ions in real seawater from the Atlantic Ocean, a second calibration/validation sample set was prepared with ion concentrations adapted to the concentrations present in such real-world matrices. Table S2 in the Supplemental Information summarizes the concentrations of each species in the calibration and validation mixtures used for the analysis of real seawater.

The validation solutions were used as quasi-unknown samples for testing the capability of the multivariate model for predicting the concentration of each ion in an unknown sample.

\section{Instrumentation}

All measurements were performed using a Bruker Vertex 70 FTIR spectrometer equipped with a temperaturecontrolled BIO-ATR II IR-ATR unit (both Bruker Optics, Ettlingen, Germany). The IR-ATR assembly enables highly sensitive measurements at minute sample volumes (i.e., $20 \mu \mathrm{L}$ ) providing temperature control from $0^{\circ} \mathrm{C}$ to $95^{\circ} \mathrm{C}$. The active sensing interface is provided by a circular silicon wafer segment with a diameter of approximately $6 \mathrm{~mm}$ and a thickness of approximately $0.5 \mathrm{~mm}$ that is coupled to a zinc selenide optical element delivering $I R$ radiation to the actual Si ATR waveguide. This configuration facilitates eight internal reflections within the Si ATR element. The IR-ATR unit was coupled to a thermostat (Lauda, Koenigshofen, Germany) for maintaining the temperature at constant values throughout the measurements. Infrared radiation was detected by a mercury-cadmium-telluride (MCT) photoconductive detector.

\section{Measurement procedure}

First, the temperature was set to a desired value and the system was equilibrated. After collecting a spectrum of ambient air as background, a spectrum for de-ionized water was recorded. After drying with a cotton swab, $20 \mu \mathrm{L}$ of the first calibration solution was pipetted onto the Si ATR waveguide, the lid was sealed, and 100 spectra were collected and averaged at a spectral resolution of $\mathrm{I} \mathrm{cm}^{-1}$. The solution was then removed with the pipette. The Si crystal was cleaned two times with $40 \mu \mathrm{L}$ of deionized water and dried with a cotton swab prior to the next experiment. This procedure was executed for each individual sample.

\section{Data processing}

The spectral region between $4000-1000 \mathrm{~cm}^{-1}$ was selected for data analysis. Several spectral regions were excluded from the analysis (i.e., spectral region selection) in order to exclude the influence of atmospheric $\mathrm{CO}_{2}$ (around $2300 \mathrm{~cm}^{-1}$ ), the influence of organic compounds (i.e., $\mathrm{CH}$ stretching vibrations at $2850 \mathrm{~cm}^{-1}$ to $3000 \mathrm{~cm}^{-1}$, and $\mathrm{C}-\mathrm{H}$ bending vibrations between $1350 \mathrm{~cm}^{-1}$ and $\left.1500 \mathrm{~cm}^{-1}\right)$, regions of high spectral noise $\left(<1038 \mathrm{~cm}^{-1}\right)$ emerging from the detector characteristics, and the intense water absorption features in this spectral region. Furthermore, spectral regions that do not provide relevant analytical information were excluded. Consequently, the following segments of the obtained IR spectra were finally included in the multivariate analysis: $3658.9-3312.7 \mathrm{~cm}^{-1}$, $3256.3-2980.0 \mathrm{~cm}^{-1}, \quad 2141.6-1864.9 \mathrm{~cm}^{-1}, \quad 1862.5-$ $1857.2 \mathrm{~cm}^{-1}, \quad 1749.7-1730.8 \mathrm{~cm}^{-1}, \quad 17 \mid 4.0-1693.7 \mathrm{~cm}^{-1}$, $1684.1-1570.8 \mathrm{~cm}^{-1}, \quad 1410.2-1166.8 \mathrm{~cm}^{-1}$ and $1157.6-$ $1038.5 \mathrm{~cm}^{-1}$ (see also Figure I(d)).

Multivariate data analysis was performed using the PSL toolbox software package (Eigenvector Inc., Manson, WA, USA) in a Matlab (TheMathWorks, Nattick, MA, USA) environment. Using selectivity ratios, spectral regions (i.e., wavenumbers) that provide relevant spectral information for the identification of each ion were identified in the calibration data set. The selectivity ratio is a numerical approach for assessing the usefulness of each variable in a multivariate model. A higher selectivity ratio indicates an increasing impact of this variable on the multivariate regression model. Variables with low selectivity ratios may thus be efficiently excluded from the analysis without affecting the performance of the model, yet limiting the contribution of noise. During this procedure, all spectral regions below a $95 \%$ confidence limit, calculated by the software, were excluded from the analysis. 

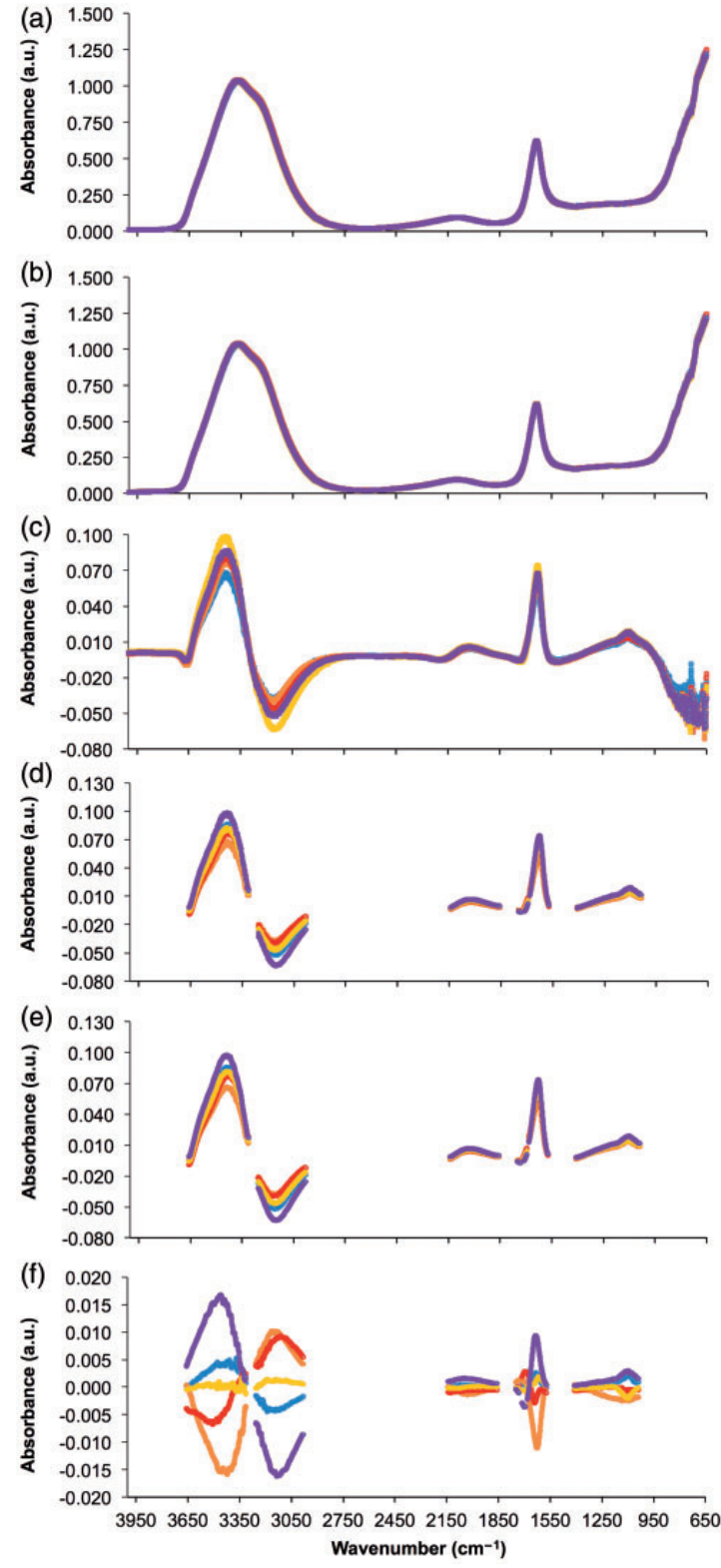

Figure I. Sequence of spectral data processing: (a) raw spectra; (b) removal of spectral features of atmospheric $\mathrm{H}_{2} \mathrm{O}$ and $\mathrm{CO}_{2}$; (c) subtraction of the spectrum of de-ionized water; (d) selection of spectral regions for analysis; (e) smoothing; (f) mean centering. For this figure, the spectra of calibrations solutions cal_I-cal_5 (see Table SI) were used to exemplarily illustrate the data processing steps.

In order to simultaneously determine different ions, PCA/PCR provided linear calibration functions for each individual ion derived from these mixtures. The resulting model suggested 20 principal components, of which the first eight were determined containing sufficient information for the prediction of the salt ion concentrations, while the remaining principal components predominantly represent noise.
In addition to concentration variations, IR spectra of each electrolyte solution were also collected at $3^{\circ} \mathrm{C}, 15^{\circ} \mathrm{C}, 22^{\circ} \mathrm{C}$, $30^{\circ} \mathrm{C}$ and $45^{\circ} \mathrm{C}$ to study the influence of different temperatures potentially occurring in real-world measurement scenarios such as marine environments. As shown, PCA/PCR could readily discriminate between different temperatures, and correctly predicted the temperature at which the spectra of the validation solutions were collected. Finally, real seawater samples were studied at $22^{\circ} \mathrm{C}$.

Figure I exemplarily illustrates processing of the raw data for spectra recorded at calibration solutions cal_Ical_5 (see Table SI). All raw spectra (Figure I(a)) were first processed using the OPUS software package (Bruker Optics, Ettlingen, Germany) via the following procedure: atmospheric compensation (i.e., removal of atmospheric water and carbon dioxide absorption features; Figure I(b)), and subtraction of the spectrum of de-ionized water from each salt-solution spectrum (Figure I(c)). The processed spectra were then imported into Matlab and further analyzed using the PSL Toolbox. Here, the spectral region selection was performed (Figure I(d)), the spectra were smoothed (Figure I(e)), and finally mean centered (i.e., the mean value for each $y$-value was calculated and subtracted from the respective $y$-value of each spectrum; Figure I(f)). Thereafter, a calibration model was established via PCR/PCA analysis. The obtained model was then crossvalidated using the venetian blinds method (i.e., 10 splits with one sample per split).

\section{Results and discussion}

As reported in our previous paper (Vogt et al., ${ }^{15}$ ) [AQ1]difference spectra of the salt solution samples against the spectrum of de-ionized water were analyzed.

The dominant absorption feature of water is the $\mathrm{O}-\mathrm{H}$ stretching band centered at $\sim 3350 \mathrm{~cm}^{-1}$ (i.e., the combination of the stretching vibration $v_{1}$, an overtone of the bending vibration $2 v_{2}$, and the stretching vibration $v_{3}$ ). The second pronounced absorption band is the libration band at $\sim 700 \mathrm{~cm}^{-1}\left(v_{\mathrm{L}}\right)$. This band appears close to the detector cut-off at $675 \mathrm{~cm}^{-1}$. Hence, this feature is distorted and was therefore not included in the data analysis. Furthermore, the $\mathrm{H}-\mathrm{O}-\mathrm{H}$ bending vibration at $\sim 1640 \mathrm{~cm}^{-1}\left(v_{2}\right)$ was included in the data analysis along with the rather weak absorption feature arising from a combination of the bending and the libration vibration at $\sim 2115 \mathrm{~cm}^{-1}$ (i.e., $v_{2}+v_{\mathrm{L}}$ ). ${ }^{40}$

Figure 2(a)-(g) illustrates the difference spectra of each salt in water recorded at two different concentrations in the $4000-1000 \mathrm{~cm}^{-1}$ spectral region. Evidently, two water absorption features reveal significant changes upon addition of salt ions. The most pronounced spectral change occurs for the $\mathrm{O}-\mathrm{H}$ stretching band at $3350 \mathrm{~cm}^{-1}$, with the band in the difference spectra appearing like a first deviation of a Gauss function. 

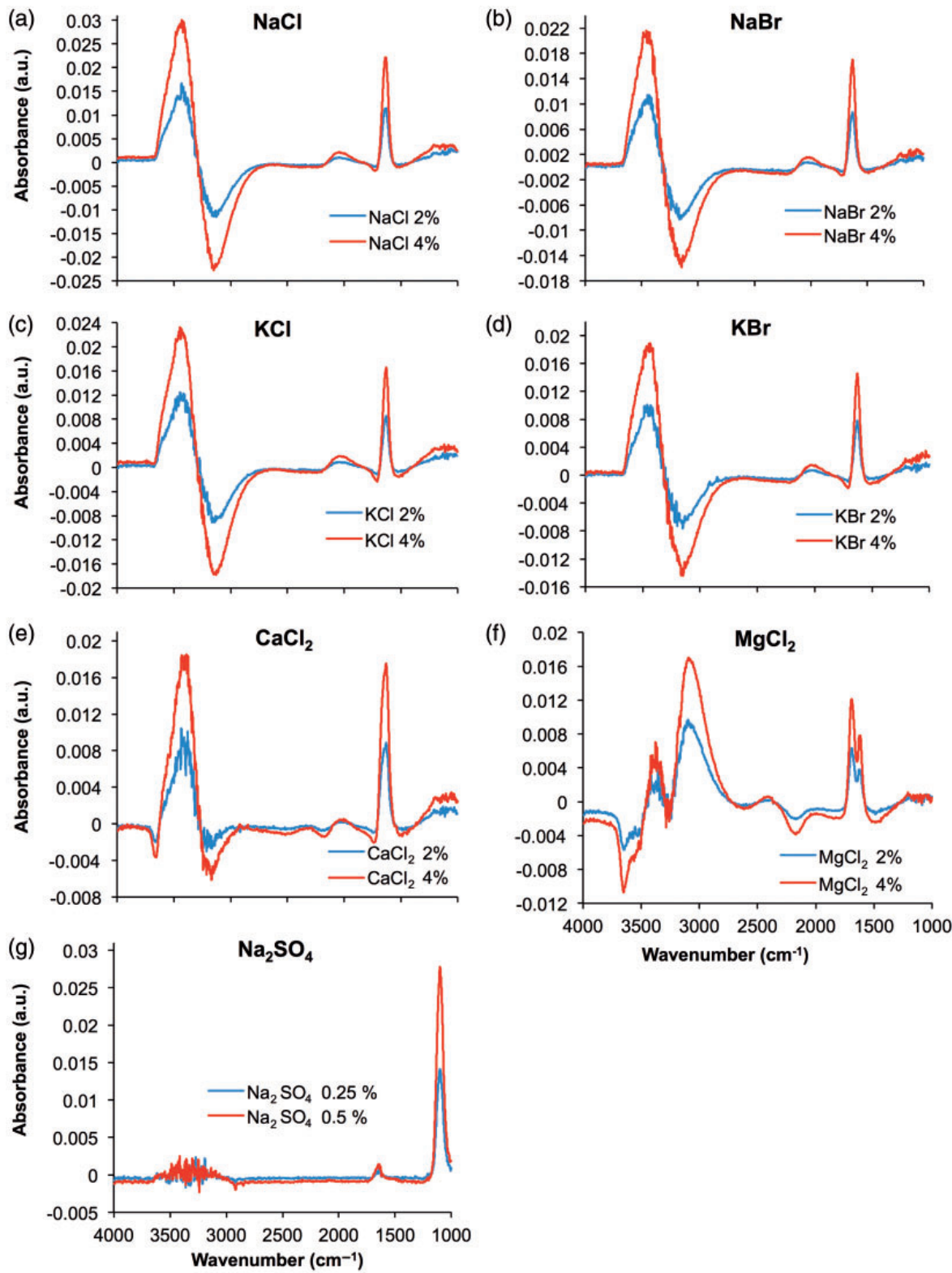

Wavenumber $\left(\mathrm{cm}^{-1}\right)$

Figure 2. Difference spectra of solutions of several salt solutions against the spectrum of de-ionized water. (a) $\mathrm{NaCl}$; (b) $\mathrm{NaBr}$; (c) $\mathrm{KCl}$; (d) $\mathrm{KBr}$; (e) $\mathrm{CaCl}_{2}$; (f) $\mathrm{MgCl}_{2}$; (g) $\mathrm{Na}_{2} \mathrm{SO}_{4}$. All spectra were collected at a resolution of $\mathrm{I} \mathrm{cm}^{-1}$ as an average of 100 scans.

In addition, the $\mathrm{H}-\mathrm{O}-\mathrm{H}$ bending vibration band of water, occurring at $\sim 1640 \mathrm{~cm}^{-1}$, is significantly affected by the organization of water molecules induced by the salt ions. In the presence of ions, the band is effectively narrowed, and the band intensity increases. This leads to a positive peak in the difference spectra with small negative bands on either side. The signals resemble the shape of the second derivative of a Gauss function. The small band representing the bending/libration vibration only reveals changes in intensity. In the spectra of the $\mathrm{CaCl}_{2}$ and the $\mathrm{MgCl}_{2}$ solutions, this band is negative, while it is not evident in the other difference spectra.
The difference spectra of the $\mathrm{Na}_{2} \mathrm{SO}_{4}$ solutions do not indicate a change of the $\mathrm{O}-\mathrm{H}$ stretching vibration described for the other spectra. The rather high noise levels evident between $3600 \mathrm{~cm}^{-1}$ and $3000 \mathrm{~cm}^{-1}$ result from the spectra subtraction, with the $\mathrm{H}-\mathrm{O}-\mathrm{H}$ bending vibration providing only small features. Here, the most prevalent spectral signature is the distinct absorption band of sulfate at $\sim 1100 \mathrm{~cm}^{-1}$. This is the characteristic absorption peak of the triply degenerate asymmetric $\mathrm{S}-\mathrm{O}$ stretching vibration $\left(v_{3}\right)$ of $\mathrm{SO}_{4}^{2-}$ in solution. ${ }^{4 \mathrm{I}}$

All spectra were collected at a temperature of $22^{\circ} \mathrm{C}$ with atmospheric compensation performed for each 
Table I. Main properties of the ions investigated during this study. Ionic radii were derived from Emsley (1989). ${ }^{42} \mathrm{For} \mathrm{SO}_{4}^{2-}$, the Pauling radius was used. ${ }^{43}$

\begin{tabular}{lcccl}
\hline lon & $\begin{array}{l}\text { Radius } \\
(\mathrm{pm})^{42}\end{array}$ & Volume $\left(\mathrm{m}^{3}\right)$ & $\begin{array}{l}\text { Charge } \\
\text { density } \\
\left(\mathrm{A} \cdot \mathrm{s} / \mathrm{m}^{3}\right)\end{array}$ & $\begin{array}{l}\text { Concentration } \\
\text { in seawater } \\
(\mathrm{Mol} / \mathrm{L})\end{array}$ \\
\hline $\mathrm{Cl}^{-}$ & $18 \mathrm{I}$ & $2.48 \times 10^{-18}$ & -0.06 & $0.545 \mathrm{I}$ \\
$\mathrm{Na}^{+}$ & 98 & $3.94 \times 10^{-19}$ & $0.4 \mathrm{I}$ & 0.4726 \\
$\mathrm{Mg}^{2+}$ & 78 & $1.99 \times 10^{-19}$ & $1.6 \mathrm{I}$ & 0.0527 \\
$\mathrm{SO}_{4}^{2-}$ & $290^{43}$ & $1.02 \times 10^{-17}$ & -0.03 & 0.0282 \\
$\mathrm{Ca}^{2+}$ & 106 & $4.99 \times 10^{-19}$ & 0.64 & 0.0103 \\
$\mathrm{~K}^{+}$ & 133 & $9.85 \times 10^{-19}$ & 0.16 & 0.0103 \\
$\mathrm{Br}^{-}$ & 196 & $3.15 \times 10^{-18}$ & -0.05 & 0.0009 \\
\hline
\end{tabular}

spectrum prior to subtraction of the spectrum of deionized water followed by smoothing (Bruker OPUS Software).

Table I gives an overview on the main properties of the ions investigated during the present study.

Evidently, $\mathrm{Na}^{+}$and $\mathrm{K}^{+}$cations have similar properties concerning size and volume charge density (on the order of approximately $0.3 \mathrm{~A} \cdot \mathrm{s} / \mathrm{m}^{3}$ ), [AQ2] and are therefore characterized by similar hydration shells. ${ }^{44}$ Also, $\mathrm{Cl}^{-}$and $\mathrm{Br}^{-}$ ions have similar properties. ${ }^{45}$ Therefore, the according IR spectra of aqueous solutions containing $\mathrm{NaCl}, \mathrm{KCl}, \mathrm{NaBr}$ and $\mathrm{KBr}$ appear similar as well. The intensities of the positive and the negative segments of the $\mathrm{O}-\mathrm{H}$ stretching feature are almost the same, with the negative part being slightly less pronounced in each spectrum. The positive feature is centered between $3459 \mathrm{~cm}^{-1}(\mathrm{NaBr})$ and $3430 \mathrm{~cm}^{-1}$ $(\mathrm{NaCl})$, while the negative peak is centered between $3150 \mathrm{~cm}^{-1}(\mathrm{NaCl})$ and $3146 \mathrm{~cm}^{-1}(\mathrm{KCl}$ and $\mathrm{NaBr})$. In the spectral region around $2115 \mathrm{~cm}^{-1}$, where the combined vibrations of bending and libration appear in the IR spectrum of pure water, there is no spectral feature evident. The $\mathrm{H}-\mathrm{O}-\mathrm{H}$ bend is centered between $1635 \mathrm{~cm}^{-1}(\mathrm{NaCl})$ and $1629 \mathrm{~cm}^{-1}(\mathrm{NaBr}, \mathrm{KCl}$ and $\mathrm{KBr})$. The differences in the hydration shells around these ions apparently are very small, and therefore similar spectral changes are induced.

In contrast, the spectrum of the $\mathrm{CaCl}_{2}$ solution already reveals distinct differences. The negative peak in the $\mathrm{O}-\mathrm{H}$ stretching region centered at $3167 \mathrm{~cm}^{-1}$ is significantly less pronounced, and a small negative feature evolves at $3656 \mathrm{~cm}^{-1}$. The positive part is centered at $3405 \mathrm{~cm}^{-1}$. The bending/libration band at $2174 \mathrm{~cm}^{-1}$ is slightly negative, and the $\mathrm{H}-\mathrm{O}-\mathrm{H}$ bending feature (centered at $1630 \mathrm{~cm}^{-1}$ ) develops a shoulder at $1665 \mathrm{~cm}^{-1}$. The apparent changes in the hydration shell are presumably evoked by the higher charge density of $\mathrm{Ca}^{2+}$, thus giving rise to a differently arranged hydration shell compared to $\mathrm{Na}^{+}$and $\mathrm{K}^{+}$.

The magnesium cation has a significantly higher volume charge density of $1.6 \mathrm{I} \mathrm{A} \cdot \mathrm{s} / \mathrm{m}^{3}$. This higher charge density evidently alters the properties of the hydration shell for $\mathrm{MgCl}_{2}$, which gives rise to distinct spectral differences compared to other salt solutions. The positive and the negative part of the spectral feature in the $\mathrm{O}-\mathrm{H}$ stretching region have switched positions. The negative part is centered at $3650 \mathrm{~cm}^{-1}$. A second negative feature appears at $3286 \mathrm{~cm}^{-1}$. The positive part is centered at $3093 \mathrm{~cm}^{-1}$ with an additional smaller maximum at $3375 \mathrm{~cm}^{-1}$. At $2174 \mathrm{~cm}^{-1}$, a negative feature is evident. Furthermore, the $\mathrm{H}-\mathrm{OH}$ bending feature reveals a distinct change by splitting into two peaks with the main peak centered at $1691 \mathrm{~cm}^{-1}$, and a smaller feature at $1621 \mathrm{~cm}^{-1}$.

The spectrum of dissolved sodium sulfate does not show significant spectral changes of the absorption features of the $\mathrm{O}-\mathrm{H}$ stretching vibration associated with $\mathrm{H}_{2} \mathrm{O}$, unlike the other salt solutions (see Figure 2(g)). The intensity of the $\mathrm{H}-\mathrm{O}-\mathrm{H}$ bending feature shows a minor increase. Obviously, this is a result of the considerably lower concentration of $\mathrm{Na}_{2} \mathrm{SO}_{4}$ in this experiment (compared to the other salts), which prevents the precipitation of gypsum. The most prevalent spectral feature is the sulfate absorption (i.e., bend feature) centered at $110 \mathrm{lcm}^{-1}$.

Table 2 gives an overview on the spectral changes upon the addition of several salts to de-ionized water. For comparison, the spectral features of pure water are included.

The review papers from Ohtaki and Radnai $(1993)^{28}$ and Marcus $(2009)^{46}$ give an overview of structural data of hydration shells, collected over the past 40 years. Two mayor parameters are used to describe this structure. One is the coordination number $(\mathrm{CN})$, which is the number of water molecules in a hydration shell. The other characteristic parameter is the distance of an ion to its nearest neighbor $\left(d_{i o n-w}\right)$. Both of these parameters are mostly measured via X-ray diffraction or neutron diffraction methods. Molecular dynamics (MD) and Monte Carlo (MC) simulations are also extensively used to study the structure of hydration shells. All of the abovementioned techniques can also be used to study the structure of the second hydration shell.

Coordination numbers obtained by diffraction techniques are around 6 for each ion studied in this work, except for the sulfate anion, which is coordinated by 6.4-12 water molecules. Computer simulations indicate a wider range of coordination numbers for the ions. For sodium and magnesium the $\mathrm{CN}$ is around 6. Potassium has a slightly higher $\mathrm{CN}$ ranging between 6.3 and 7.8, whilst the $\mathrm{CN}$ of calcium lies between 9.2 and 9.6. For chloride, a wider distribution of hydration numbers is reported, ranging as far as 1-8, 4-13 or 6-10. For bromide a $\mathrm{CN}$ of 8 is reported, whilst the computed $\mathrm{CN}$ of the sulfate anion is lower than 6.

The distance of sodium to the nearest water molecules (first hydration shell) is determined experimentally at 240-250 pm, while the computed value ranges between $230 \mathrm{pm}$ and $240 \mathrm{pm}$. For potassium ions the distance to 
Table 2. Overview on the spectral changes upon addition of different salts to de-ionized water.

\begin{tabular}{|c|c|c|c|c|c|c|}
\hline \multirow[b]{3}{*}{ Salt } & \multicolumn{6}{|l|}{ Spectral feature } \\
\hline & \multicolumn{2}{|l|}{$\mathrm{O}-\mathrm{H}$ stretch } & \multirow[b]{2}{*}{$\begin{array}{l}\text { Bending vibration/3rd } \\
\text { libration overtone }\left(\mathrm{cm}^{-1}\right)\end{array}$} & \multicolumn{2}{|c|}{$\mathrm{H}-\mathrm{O}-\mathrm{H}$ bending } & \multirow[b]{2}{*}{$\begin{array}{l}\text { S-O stretch } \\
\left(\mathrm{cm}^{-1}\right)\end{array}$} \\
\hline & $\begin{array}{l}\text { Positive } \\
\text { part }\left(\mathrm{cm}^{-1}\right)\end{array}$ & $\begin{array}{l}\text { Negative } \\
\text { part }\left(\mathrm{cm}^{-1}\right)\end{array}$ & & $\begin{array}{l}\text { Main } \\
\text { peak }\left(\mathrm{cm}^{-1}\right)\end{array}$ & $\begin{array}{l}\text { Second } \\
\text { peak }\left(\mathrm{cm}^{-1}\right)\end{array}$ & \\
\hline $\mathrm{NaCl}$ & 3430 & 3150 & l & 1635 & l & l \\
\hline $\mathrm{NaBr}$ & 3459 & 3146 & I & 1629 & l & I \\
\hline $\mathrm{KCl}$ & 3447 & 3146 & 1 & 1629 & I & 1 \\
\hline $\mathrm{KBr}$ & 3434 & 3149 & 1 & 1629 & 1 & 1 \\
\hline $\mathrm{CaCl}_{2}$ & 3405 & 3656 and 3167 & 2174 (negative) & 1630 & 1665 shoulder & 1 \\
\hline $\mathrm{MgCl}_{2}$ & 3375 and 3093 & 3650 and 3286 & 2174 (negative) & 1691 & $162 \mid$ & I \\
\hline $\mathrm{Na}_{2} \mathrm{SO}_{4}$ & Artifacts & Artifacts & 1 & 1650 & I & 1101 \\
\hline $\mathrm{H}_{2} \mathrm{O}$ & 3315 & 1 & 2118 & 1637 & I & 1 \\
\hline
\end{tabular}

the nearest neighbor is $260-295 \mathrm{pm}$ (diffraction methods) or $27 \mathrm{I}-286 \mathrm{pm}$ (computer simulations) according to the literature. Calcium cations have a similar distance to their hydration shell as sodium ions. Values between $233 \mathrm{pm}$ and $244 \mathrm{pm}$ (experimentally) and 239-254 pm (computed) are reported. Obviously, $\mathrm{Mg}^{2+}$ ions form the smallest hydration shell amongst the studied ions. The experimental values for $d_{\mathrm{Mg}-\mathrm{W}}$ range from $204 \mathrm{pm}$ to $215 \mathrm{pm}$, while the computed values are between $200 \mathrm{pm}$ and $205 \mathrm{pm}$. The anions form bigger hydration shells than the cations do. Chloride anions have a $d_{\mathrm{Cl}-\mathrm{W}}$ of (mostly) 310-320 pm (experimentally) or 270-350 pm (computed). Bromide ions are 329-340 pm away from their nearest neighbor molecules. For $\mathrm{SO}_{4}^{2-}$, values between $370 \mathrm{pm}$ and $393 \mathrm{pm}$ are reported. Both of these values were determined by diffraction methods. The calculated distance between the bromide anion and its nearest neighbor is between $327 \mathrm{pm}$ and $337 \mathrm{pm},{ }^{47}$ while it is $382 \mathrm{pm}$ for the sulfate anion (the distance between the sulfur atom and the nearest oxygen atom from a water molecule). ${ }^{48}$

Since the (experimentally) determined coordination numbers are more or less the same, the distance between the ion and the water molecules in the hydration shell seems to be primarily responsible for the changes induced into the spectrum of pure water. Since infrared radiation excites vibration and rotation of bonds in molecules, it is absolutely logical that the "binding" distance of ion and water, which also influences the $\mathrm{H}$-bonding of the respective water molecule to its neighboring water molecules, has a major impact on the IR spectrum of water. Of course, the orientation of the water molecules inside a hydration shell as well as the structure and size of the second hydration shell are considered to contribute to the spectral changes. Unfortunately, the data concerning both of these parameters is not very consistent and therefore no reliable conclusions can be drawn.

\section{Simultaneous determination of seven ions in water}

Although there are only subtle spectral differences induced by the various salts in solutions, a PCR model enabling discriminating between $\mathrm{Cl}^{-}, \mathrm{Na}^{+}, \mathrm{Mg}^{2+}, \mathrm{SO}_{4}^{2-}, \mathrm{Ca}^{2+}, \mathrm{K}^{+}$ and $\mathrm{Br}^{-}$was successfully established. In addition to the quantitative determination of salt ions in different mixtures (see Table SI), five different temperatures have been added as additional variable deriving linear calibration functions for each salt at each temperature. Figure 3 exemplarily illustrates the calibration function for $\mathrm{Mg}^{2+}$ at $22^{\circ} \mathrm{C}$ plotting the known concentration (i.e., measured concentration) against the predicted concentration values obtained via PCR analysis. The dashed grey line in Figure 3 represents all values where measured and predicted concentrations are equal, which corresponds to an ideal fit. The solid blue line represents the linear function fitted to the obtained calibration values.

Evidently, the predicted values are in excellent agreement with the known concentrations. Also, quasiunknown concentrations of the validation measurements (i.e., red dots) were correctly predicted by the model.

The predicted values for each ion were then used for establishing linear calibration functions (Figure 3(a)). For that purpose, mean values of the predicted concentrations (i.e., five predicted values per concentration) were calculated and plotted vs. the real concentration. The standard deviations of the predicted values per real concentration value were for indicating negative and positive errors (Figure 3(b)).

While excellent linear regressions were obtained for $\mathrm{Cl}^{-}, \mathrm{SO}_{4}^{2-}, \mathrm{Mg}^{2+}, \mathrm{Ca}^{2+}$ and $\mathrm{Br}^{-}, \mathrm{Na}^{+}$and $\mathrm{K}^{+}$revealed lower $\mathrm{R}^{2}$ values, which was attributed to the pronounced similarity of these ions and the resultant mutual influence within the PCR model. Nevertheless, both ions could be simultaneously quantified within the validation solutions. 
(a)
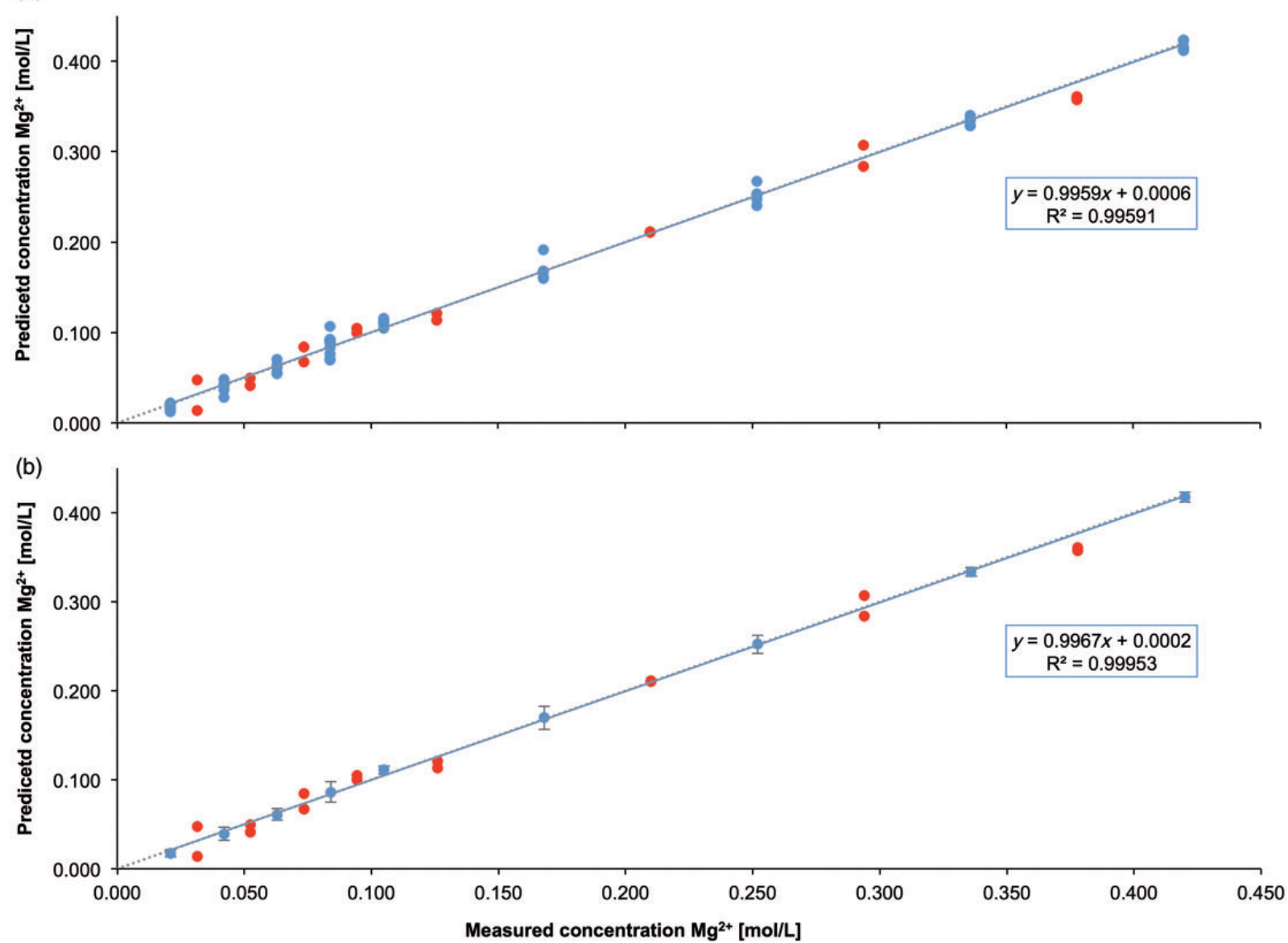

Figure 3. Calibration of $\mathrm{Mg}^{2+}$ in the range of $0.02-0.42 \mathrm{~mol} / \mathrm{L}$ in solutions of seven different salts. The blue dots represent the calibration values, and the red dots represent the validation measurements. The solid black line is the linear regression plot for the calibration samples. The dashed grey line illustrates the "ideal" I:I fit. The standard deviation (of five values for each calibration value) was used as negative and positive error. [AQ8]

Figure 4 shows the calibrations and the validation measurements for $\mathrm{Cl}^{-}, \mathrm{Na}^{+}, \mathrm{SO}_{4}^{2-}, \mathrm{Ca}^{2+}, \mathrm{K}^{+}$and $\mathrm{Br}^{-}$at $22^{\circ} \mathrm{C}$.

For the calibrations of $\mathrm{Cl}^{-}, \mathrm{Na}^{+}, \mathrm{K}^{+}$and $\mathrm{Br}^{-}$, no errors could be calculated as they originate from several salts in the mixtures (e.g., $\mathrm{Cl}^{-}$is present in $\mathrm{NaCl}, \mathrm{KCl}, \mathrm{MgCl}_{2}$ and $\mathrm{CaCl}_{2}$ ). This leads to an individual concentration of each of the mentioned ions in each calibration and validation mixture.

Since the determination of detection limits in multivariate data analysis are subject to ongoing discussions, ${ }^{49,50}$ the limit of detection (LOD) for all ions except for $\mathrm{SO}_{4}^{2-}$ was estimated at $0.025 \mathrm{~mol} / \mathrm{L}$ [AQ3]. Due to the distinct IR characteristics of $\mathrm{SO}_{4}^{2-}$ at $\sim 1100 \mathrm{~cm}^{-1}$, the limit of detection for the sulfate anion was estimated at $\sim 0.00 \mathrm{I} \mathrm{mol} / \mathrm{L}$.

\section{Influence of temperature}

Figure 5(a) shows the prediction functions for five different temperatures. All calibration spectra were collected at $3^{\circ} \mathrm{C}$, $15^{\circ} \mathrm{C}, 22^{\circ} \mathrm{C}, 30^{\circ} \mathrm{C}$ and $45^{\circ} \mathrm{C}$. The calibration model applied for discriminating and quantifying the ions was adapted for prediction of the temperature of the validation samples as an additional variable.

The dashed grey line indicates perfect correspondence between measured and predicted values. The blue line represents the resulting linear regression/calibration function for the temperature. Each calibration point is the mean value of 50 measurements, as all calibration solutions (see Table $\mathrm{SI}$ ) as well as the diluted calibration solutions were included in the model. The standard deviation was calculated, and used as positive and negative errors. Despite deviations from the ideal plot, especially for the predicted value of $45^{\circ} \mathrm{C}$, the temperatures at which the spectra of the validation sets were collected were correctly predicted by the model with excellent accuracy (e.g., $\pm 2.2^{\circ} \mathrm{C}$ at $45^{\circ} \mathrm{C}$ ).

Obviously, temperature affects the spectral data, which is recognized by the PCR with a maximum of the selectivity ratio for the prediction of the temperature at $3642 \mathrm{~cm}^{-1}$. 

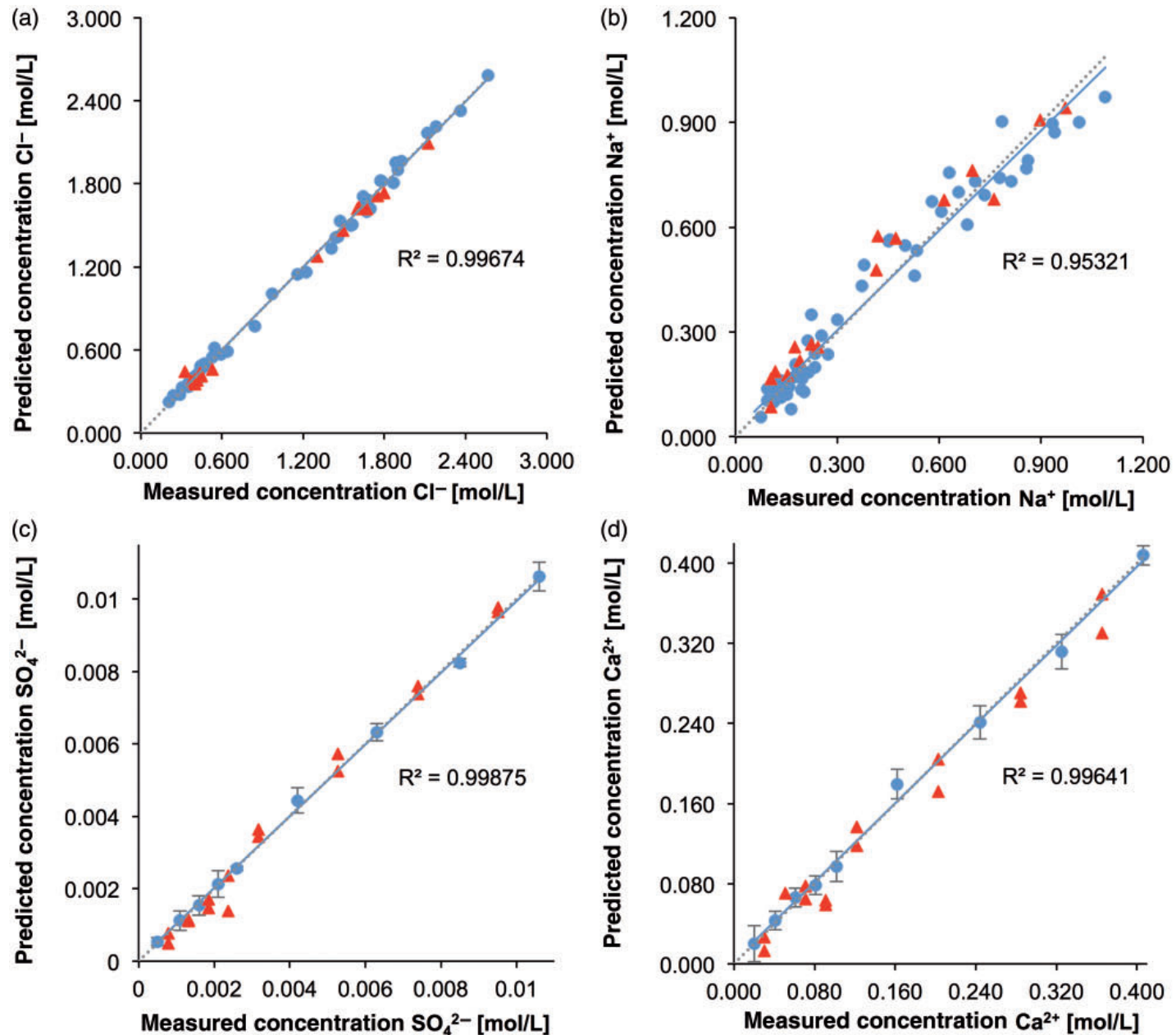

(d)
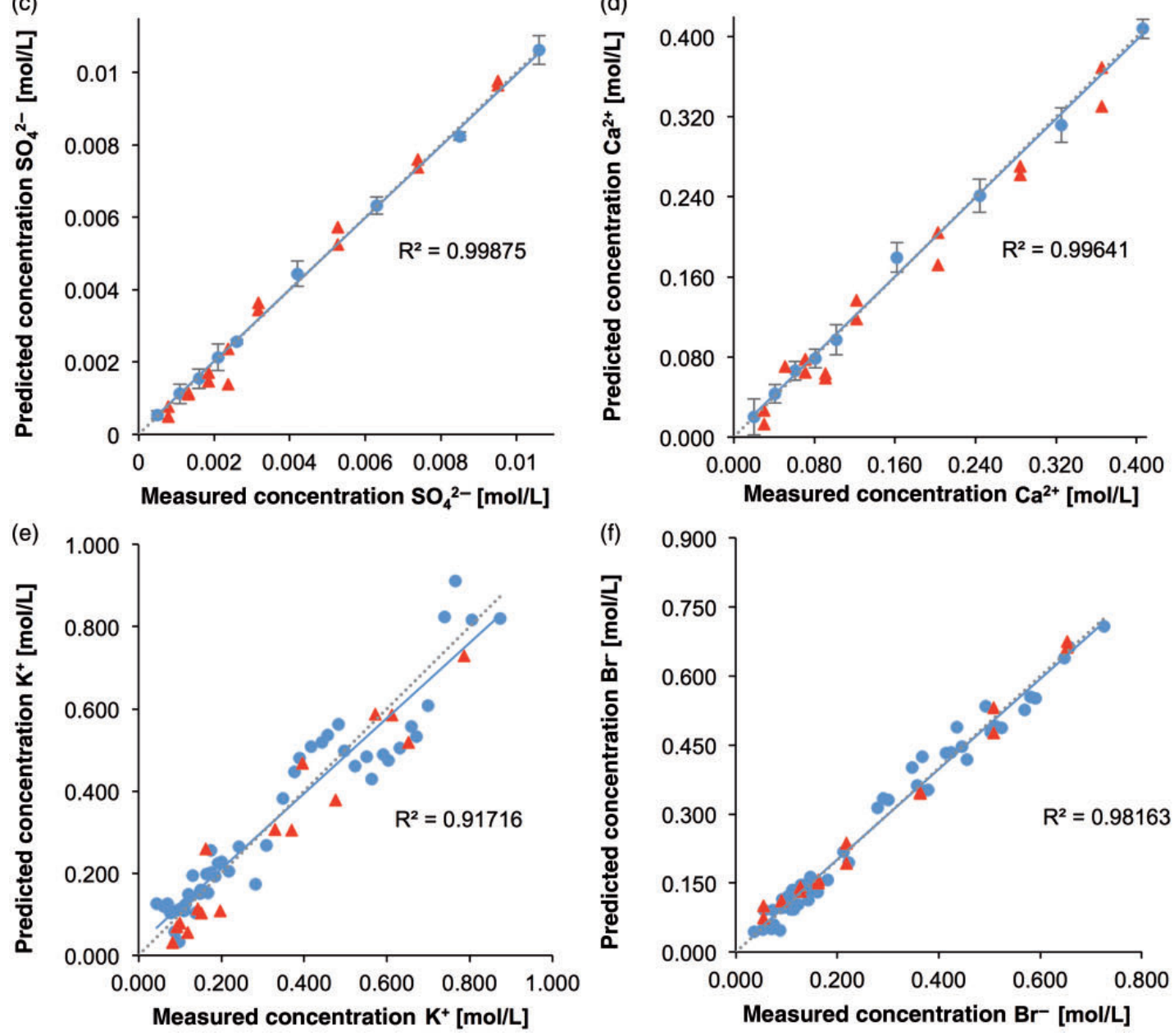

Figure 4. Linear calibration functions for (a) $\mathrm{Cl}^{-}$; (b) $\mathrm{Na}^{+}$; (c) $\mathrm{SO}_{4}^{2-}$; (d) $\mathrm{Ca}^{2+}$; (e) $\mathrm{K}^{+}$and (f) $\mathrm{Br}^{-}$at $22^{\circ} \mathrm{C}$. Blue dots represent the calibration measurements, and red triangles represent the validation measurements. The grey dashed line indicates perfect correspondence of measured vs. predicted concentration.

This indicates that in this spectral region temperature changes affect the obtained spectra most, while the contribution of the dissolved ions appears to be minimal. Figure 5(b) shows the mid-IR spectra of solution cal_I (see Table $\mathrm{SI}$ in the supporting information) at five different temperatures $\left(3^{\circ} \mathrm{C}, 15^{\circ} \mathrm{C}, 22^{\circ} \mathrm{C}, 30^{\circ} \mathrm{C}\right.$ and $\left.45^{\circ} \mathrm{C}\right)$ with a detailed view of the region between $3620 \mathrm{~cm}^{-1}$ and $3750 \mathrm{~cm}^{-1}$. Within this spectral region, a small negative 

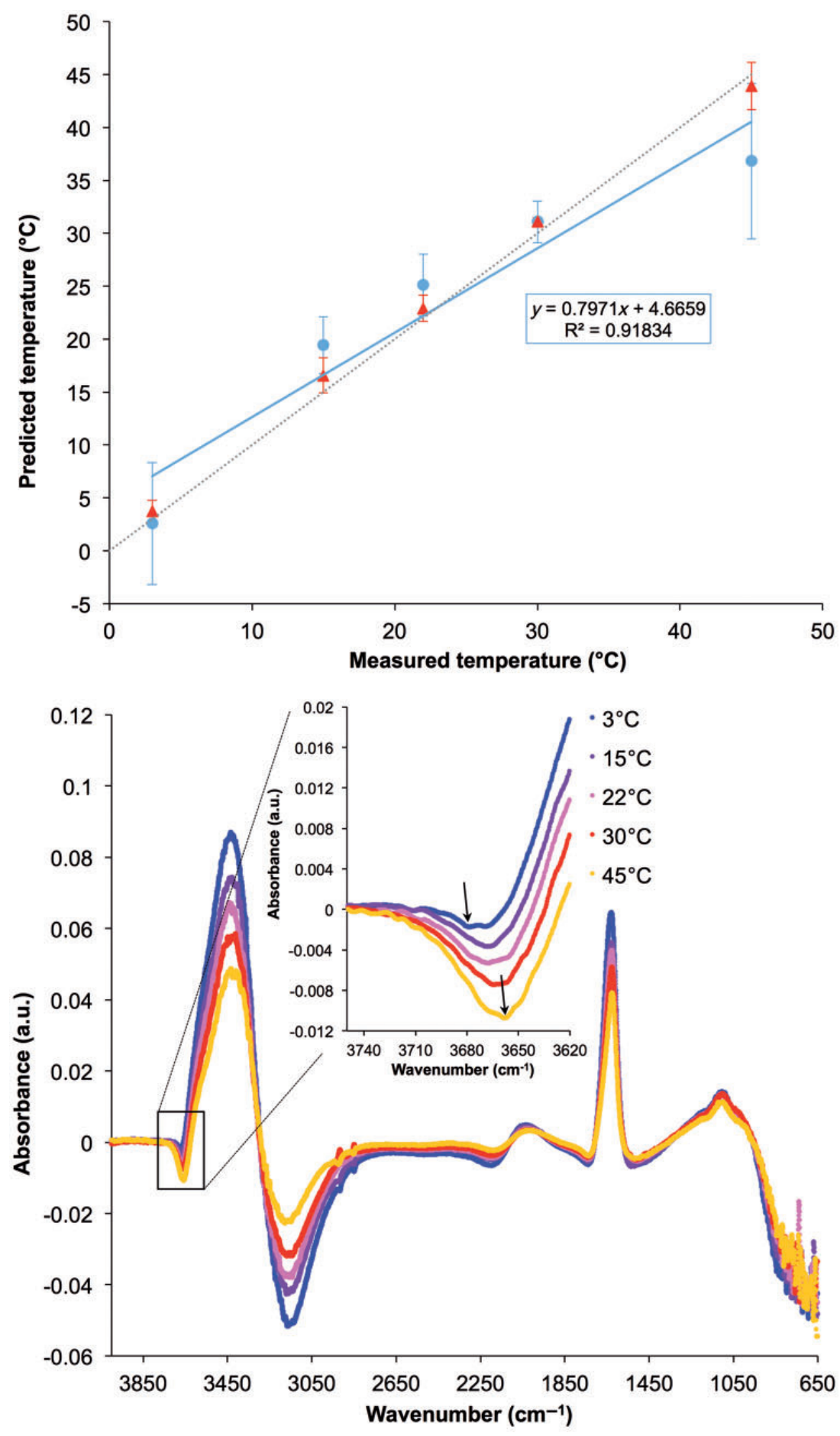

Figure 5. (a) Linear prediction function for the temperature at which the IR spectra were collected. (b) Spectra of solution cal_I (see Table SI) at five different temperatures $\left(3^{\circ} \mathrm{C}, 15^{\circ} \mathrm{C}, 22^{\circ} \mathrm{C}, 30^{\circ} \mathrm{C}\right.$ and $\left.45^{\circ} \mathrm{C}\right)$, with a detailed view on the spectral region between $3620 \mathrm{~cm}^{-1}$ and $3750 \mathrm{~cm}^{-1}$. Arrows indicate the shift of the peak minimum from $3678 \mathrm{~cm}^{-1}$ at $3^{\circ} \mathrm{C}$ to $3658 \mathrm{~cm}^{-1}$ at $45^{\circ} \mathrm{C}$. All spectra were collected at a resolution of $1 \mathrm{~cm}^{-1}$ as an average of 100 scans.

feature occurs in the difference spectra next to the dominating $\mathrm{O}-\mathrm{H}$ stretching feature with decreasing intensity at increasing temperature. Also, the peak minimum slightly shifts from $3678 \mathrm{~cm}^{-1}$ to $3658 \mathrm{~cm}^{-1}$ in the range of $3^{\circ} \mathrm{C}$ to $45^{\circ} \mathrm{C}$, as indicated by arrows in the detailed view (Figure 5).

In pure water, the $\mathrm{O}-\mathrm{H}$ stretching band can be satisfactorily described by three Gaussian peaks, one of which is 

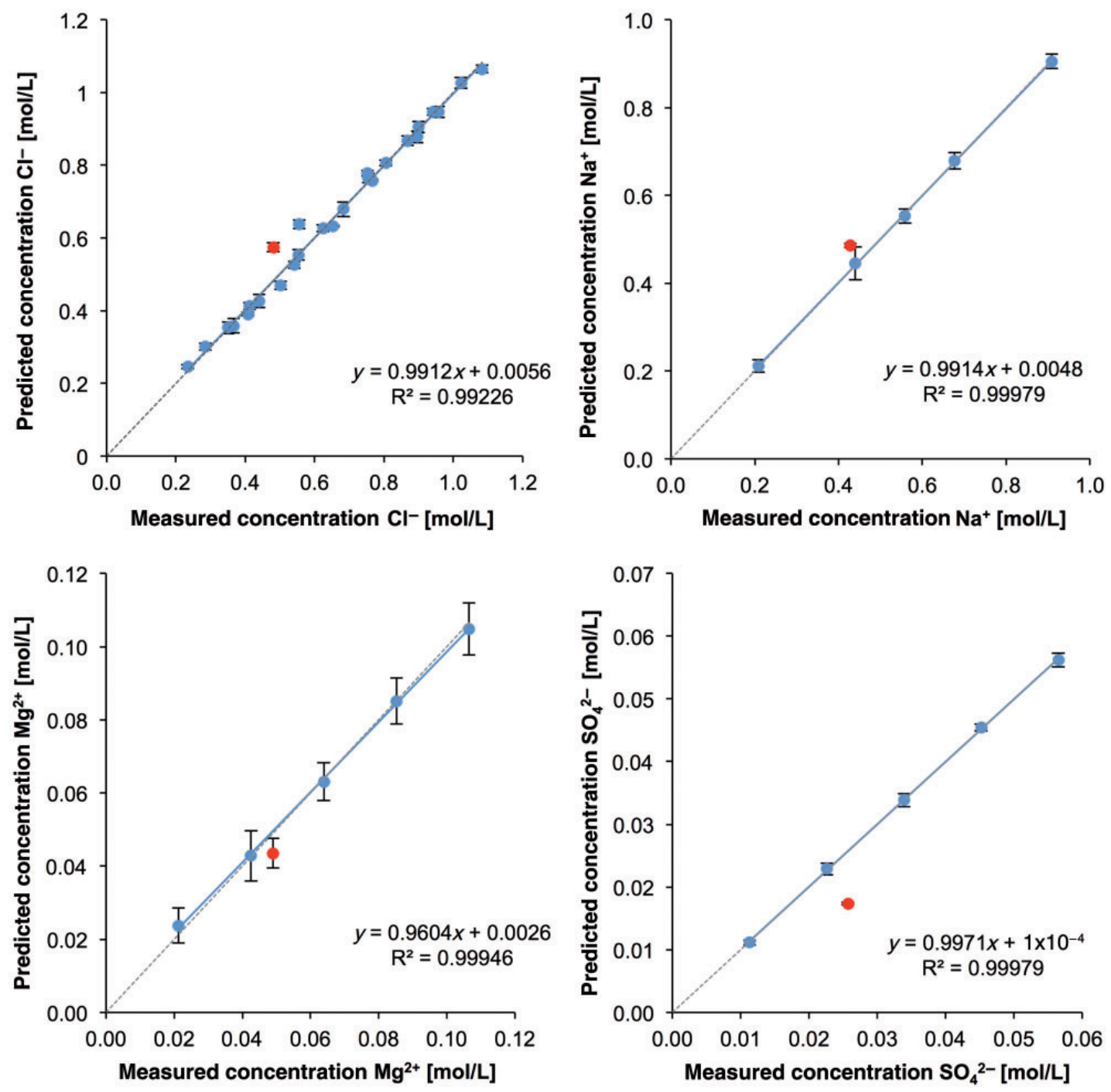

Figure 6. Calibrations for (a) $\mathrm{Cl}^{-}$; (b) $\mathrm{Na}^{+}$; (c) $\mathrm{Mg}^{2+}$ and (d) $\mathrm{SO}_{4}^{2-}$ in a sample of real seawater from the Atlantic Ocean. Blue dots represent the calibration samples, and the dashed grey line indicates perfect correspondence between measured and predicted concentration values. The red dots represent the predicted concentrations of each ion in the real world sample.

centered at $3590 \mathrm{~cm}^{-1}$. This peak is assigned to so-called 'multimer water', which translates into poorly H-bonded water molecules resembling water dimers (i.e., the peak maximum of dimeric water is located at $\left.3640 \mathrm{~cm}^{-1}\right)$. Since water molecules represented by this absorption feature are considered to be poorly bound to their environment, they may be considered an indicator for the grade of organization of the water molecules. With decreasing temperature, the intensity of this Gaussian peak is apparently decreasing, ${ }^{51-54}$ which also causes a slight shift of this feature within the difference spectra. Evidently, this band is influenced by ions in a different way compared to temperature changes with ions 'structuring' water molecules that are loosely bound more easily compared to strongly bound/ assembled water clusters. In turn, this would support the hypothesis that the interaction of ions with these water molecules is more pronounced at higher temperatures, which is evidently reflected in the recorded spectra. The $\mathrm{Mg}^{2+}$ ion appears to play an especially important role in this process, as it induces a strongly pronounced negative spectral feature in this region, as shown in Figure 2(f) and Table 2.

\section{Analysis of real seawater}

Even though the background matrix for establishing the calibration model vs. a real-world sample is different, it was tested whether seawater from the Atlantic Ocean might be analyzed with the quantification model established herein. Therefore, a new calibration set was prepared containing each salt at a concentration approximating the concentrations usually present in seawater (see Table S2). 
Table 3. Overview of the predicted concentrations for each ion including reference values and mean concentrations in seawater.

\begin{tabular}{llll}
\hline Ion & $\begin{array}{l}\text { Mean concentration } \\
\text { in seawater }(\mathrm{mol} / \mathrm{L})\end{array}$ & Reference value $(\mathrm{mol} / \mathrm{L})$ & Predicted value $(\mathrm{mol} / \mathrm{L})$ \\
\hline $\mathrm{Cl}^{-}$ & $0.545 \mathrm{I}$ & $0.48 \mathrm{II} \pm 0.0010$ & $0.5739 \pm 0.012 \mathrm{I}$ \\
$\mathrm{Na}^{+}$ & 0.4726 & $0.4282 \pm 0.0022$ & $0.4864 \pm 0.0049$ \\
$\mathrm{Mg}^{2+}$ & 0.0527 & $0.0490 \pm 0.0008$ & $0.0435 \pm 0.0040$ \\
$\mathrm{SO}_{4}^{2-}$ & 0.0282 & $0.0257 \pm 0.0004$ & $0.0174 \pm 0.0002$ \\
$\mathrm{Ca}^{2+}$ & 0.0103 & $0.0092 \pm 0.0002$ & Below LOD \\
$\mathrm{K}^{+}$ & 0.0103 & $0.0088 \pm 0.0002$ & Below LOD \\
$\mathrm{Br}^{-}$ & 0.0009 & $0.0009 \pm 0.000 \mathrm{I}$ & Below LOD \\
\hline
\end{tabular}

Linear calibration functions were obtained for four of the ions $\left(\mathrm{Cl}^{-}, \mathrm{Na}^{+}, \mathrm{Mg}^{2+}\right.$ and $\left.\mathrm{SO}_{4}^{2-}\right)$. The concentrations of the other ions are below the estimated limit of detection of the method developed in this study. Figure 6 shows the calibration plots for chloride, sodium, magnesium and sulfate (blue dots and line). Furthermore, the analysis of the respective ion contained in a real seawater sample is indicated (red dots). The dashed grey line indicates perfect correspondence between measured and predicted concentration values.

Accurate calibration functions were obtained for each ion; for validation, the ion content of the real seawater sample was also quantified via inductively coupled plasma optical emission spectroscopy (ICP-OES) measurements. Furthermore, the reference value for the chloride anion, which is difficult to obtain during OES analysis, was obtained by titration of the seawater sample with silver nitrate solution using potassium chromate as indicator. Since bromide also precipitates during this titration, the obtained concentration was corrected by subtracting the concentration of $\mathrm{Br}^{-}$, which was derived from the ICP-OES analysis. The errors for the reference values were calculated as the standard deviation averaging three independently measured values for each ion. The errors for the predicted values from the multivariate model are represented by the standard deviation of five measurements averaged for each ion. Although ICP-OES suffers from limitations for trace constituent analysis (i.e., especially trace metals) in seawater, it is sufficiently accurate and precise for the determination of major constituents in marine matrices including salt ions. The concentrations determined via ICP-OES were in excellent agreement with the reference values provided by the seawater supplier.

The predicted concentration of chloride is $19.3 \%$ higher than the reference value obtained by titration, but within the range of the mean concentrations of $\mathrm{Cl}^{-}$in seawater. The amount of sodium in the seawater sample was predicted at $0.4864 \mathrm{~mol} / \mathrm{L}$, which is $13.6 \%$ higher than the reference value, yet again in agreement with the mean concentration of sodium in seawater. The predicted concentration of $\mathrm{Mg}^{2+}$ was $11.2 \%$ lower than the value obtained by ICP-OES. The sulfate concentration calculated by the model was $32.3 \%$ lower than the reference value. Since ICP-OES quantifies the total amount of sulfur, the reference value also includes sulfur from organic compounds and, therefore, may overpredict the total sulfur content within the seawater sample. Table 3 provides an overview of the results quantifying several ions in a real seawater sample from the Atlantic Ocean.

\section{Conclusions}

In this study, a method for the simultaneous quantitative determination of seven different ions in saltwater mixtures via infrared attenuated total reflection (IR-ATR) spectroscopy was further evolved, now including temperature as an additional variable. Validation samples were analyzed for testing the predictive power of the obtained multivariate model. Finally, a sample of real seawater from the Atlantic Ocean was analyzed using an adapted calibration sample set. Thereby, a PCR model was established that could accurately discriminate between seven salt ions at five different temperatures. Furthermore, the model correctly predicted the concentrations within synthetically prepared validation samples. Last but not least, temperature was introduced as an additional variable into the multivariate model, and the PCA model facilitated correct predictions of the temperature at which the validation solution spectra were collected. This feature is of particular importance for considering in-field applications of IR sensing technologies in marine environments. Finally, four out of seven ions could be simultaneously quantified in a real seawater sample (i.e., $\mathrm{Cl}^{-}, \mathrm{Na}^{+}, \mathrm{Mg}^{2+}$ and $\mathrm{SO}_{4}^{2-}$ ) with the concentrations of $\mathrm{Ca}^{2+}, \mathrm{K}^{+}$and $\mathrm{Br}^{-}$remaining below the achievable limits of detection.

Given the potential of IR spectroscopy for indirectly analyzing IR-inactive species, future studies will focus on alternative ion mixtures for, e.g., monitoring nutrients or ionic pollutants in residential or industrial wastewaters. Given the recently reported advances currently evident in 
miniaturized IR-ATR sensor technology, ${ }^{55-59}$ such sensors may be operated in situ for simultaneous online monitoring of ions and organic constituents in aqueous media, and specifically in marine environments.

\section{Acknowledgments}

Sylvia Mauthe and Juliana Fiechtner are thanked for measurements during their laboratory courses at IABC that have in part contributed to this study.

\section{Conflict of Interest}

None declared.

\section{Funding}

This work was supported by the European Union FP7 project SCHeMA-Integrated in Situ Chemical Mapping Probes (grant agreement number 6I4002).

\section{Supplemental material}

All supplemental material mentioned in the text, including two tables, is available in the online version of the journal, at http:// asp.sagepub.com/supplemental.

\section{References}

I. M.E.Q. Pilson. "Salinity, Chlorinity, Conductivity, and Density". In: An Introduction to the Chemistry of the Sea. New York: Cambridge University Press, 2013. Pp. 46-64.

2. A. Fairbanks. "Empedokles". In: The First Philosophers of Greece. London: K. Paul, Trench, Trübner \& Co., Ltd., I898. Pp. 157-234.

3. Pliny the Elder, P. Holland. "The Power of the Sun, and Why the Sea is Salt". In: Pliny's Natural History. In thirty-seven books. London: Printed for the Wernerian Club by G. Barclay, 1847. Book II. Pp. 136-137.

4. Aristotle. "Meteorology". In: Complete Works of Aristotle, Volume 2: The Revised Oxford Translation. Princeton: Princeton University Press, 2014.

5. A.-L. de Lavoisier. "Mémoire sur I'Usage de l'Esprit-de-Vin dans l'Analyse des Eaux Minerals”. Mém. L’Academie R. Sci. Paris Année 1772. I776. 2: 555-563.

6. E. Wicke, W.A.P. Luck (eds.). "Structure of Water and Aqueous Solutions: Proceedings of the Internat. Symposium Marburg 1973". Weinheim (Bergstr.): Verlag Chemie GmbH und Physik Verlag $\mathrm{GmbH}, 1974$.

7. H. Kleeberg. "Interactions of Water in Ionic and Nonionic Hydrates: Proceedings of a Symposium in Honour of the 65th Birthday of W.A.P. Luck, Marburg/FRG, 2.-3.4. 1987”. Berlin: Springer Berlin Heidelberg, 1987.

8. T. Hirschfeld. "Salinity Determination Using NIRA". Appl. Spectrosc. 1985. 39(4): 740-74I.

9. J. Lin, J. Zhou, C.W. Brown. "Identification of Electrolytes in Aqueous Solutions from Near-IR Spectra”. Appl. Spectrosc. 1996. 50(4): 444-448.

10. H.M. Heise, A. Bittner. "Essential Absorption Data for In-Vitro and InVivo Near Infrared Spectrometric Biotic Fluid Assays". AIP Conf. Proc. 1998. 430(274): 274-277.

II. G.W. Steen, E.C. Fuchs, A.D. Wexler, H.L. Offerhaus. "Identification and Quantification of 16 Inorganic lons in Water by Gaussian Curve Fitting of Near-Infrared Difference Absorbance Spectra". Appl. Opt. 2015. 54(19): 5937.
12. B. Mizaikoff. "Mid-Infrared Evanescent Wave Sensors-a Novel Approach for Subsea Monitoring”. Meas. Sci. Technol. 1999. 10(I2): II85.

13. M. Kraft, B. Mizaikoff. "A Mid-Infrared Sensor for Monitoring of Chlorinated Hydrocarbons in the Marine Environment". Int. J. Environ. Anal. Chem. 2000. 78(3-4): 367-383.

14. M. Kraft, M. Jakusch, M. Karlowatz, A. Katzir, B. Mizaikoff. "New Frontiers for Mid-Infrared Sensors: Towards Deep Sea Monitoring with a Submarine FT-IR Sensor System”. Appl. Spectrosc. 2003. 57(6): 59I-599.

15. F. Vogt, M. Kraft, B. Mizaikoff. "First Results on Infrared Attenuated Total Reflection Spectroscopy for Quantitative Analysis of Salt lons in Seawater". Appl. Spectrosc. 2002. 56(10): I376-1380.

16. V.J. Frost, K. Molt. "Analysis of Aqueous Solutions by Near-Infrared Spectrometry (NIRS) III. Binary Mixtures of Inorganic Salts in Water". J. Mol. Struct. 1997. 410-41 I: 573-579.

17. J.-J. Max, C. Ménichelli, C. Chapados. "Infrared Titration of Aqueous Sulfuric Acid”. J. Phys. Chem. A. 2000. I04(I2): 2845-2858.

I8. J.-J. Max, C. Chapados. "IR Spectroscopy of Aqueous Alkali Halide Solutions: Pure Salt-Solvated Water Spectra and Hydration Numbers". J. Chem. Phys. 200I. II5(6): 2664-2675.

19. J.-J. Max, S. de Blois, A. Veilleux, C. Chapados. "IR Spectroscopy of Aqueous Alkali Halides. Factor Analysis”. Can. J. Chem. 200I. 79(I): |3-2|.

20. K.D. Collins, G.W. Neilson, J.E. Enderby. "lons in Water: Characterizing the Forces that Control Chemical Processes and Biological Structure”. Biophys. Chem. 2007. I28(2-3): 95-I04.

2I. R.J. Cooper, T.M. Chang, E.R. Williams. "Hydrated Alkali Metal lons: Spectroscopic Evidence for Clathrates”. J. Phys. Chem. A. 2013. I I7(30): 657|-6579.

22. P. Kebarle. "Ion Thermochemistry and Solvation from Gas Phase Ion Equilibria”. Annu. Rev. Phys. Chem. 1977. 28(I): 445-476.

23. A.W. Castleman, R.G. Keesee. "Ionic Clusters". Chem. Rev. 1986. 86(3): 589-618.

24. J.V. Coe. "Connecting Cluster lons and Bulk Aqueous Solvation: A New Determination of Bulk Single Ion Solvation Enthalpies". Chem. Phys. Lett. 1994. 229(I-2): 16I-168.

25. P. Ayotte, C.G. Bailey, G.H. Weddle, M.A. Johnson. "Vibrational Spectroscopy of Small Br--( $\left(\mathrm{H}_{2} \mathrm{O}\right) \mathrm{n}$ and I-. $\left(\mathrm{H}_{2} \mathrm{O}\right)$ n Clusters: Infrared Characterization of the lonic Hydrogen Bond". J. Phys. Chem. A. 1998. 102(I8): 3067-307I.

26. H. Gai, L.X. Dang, G.K. Schenter, B.C. Garrett. "Quantum Simulation of Aqueous Ionic Clusters". J. Phys. Chem. 1995. 99(36): I3303-13306.

27. D. Laria, R. Fernandez-Prini. "Ion-Pair Solvation in Aqueous Clusters". Chem. Phys. Lett. 1993. 205(2-3): 260-266.

28. H. Ohtaki, T. Radnai. "Structure and Dynamics of Hydrated lons". Chem. Rev. 1993. 93(3): II57-1204.

29. R. Buchner, S.G. Capewell, G. Hefter, P.M. May. "Ion-Pair and Solvent Relaxation Processes in Aqueous $\mathrm{Na}_{2} \mathrm{SO}_{4}$ Solutions”. J. Phys. Chem. B. 1999. 103(7): I185-1192.

30. J.-J. Max, C. Chapados. "Interpolation and Extrapolation of Infrared Spectra of Binary Ionic Aqueous Solutions". Appl. Spectrosc. 1999. 53(I2): 160I-1609.

3I. K.J. Tielrooij, N. Garcia-Araez, M. Bonn, H.J. Bakker. "Cooperativity in Ion Hydration”. Science. 2010. 328(598I): 1006-1009.

32. K. Pearson. "LIII. On Lines and Planes of Closest Fit to Systems of Points in Space”. Philos. Mag. Ser. 6. 190I. 2(II): 559-572.

33. S. Wold, K. Esbensen, P. Geladi. "Principal Component Analysis". Chemom. Intell. Lab. Syst. 1987. 2(I-3): 37-52.

34. R.G. Brereton. "Chemometrics: Data Analysis for the Laboratory and Chemical Plant”. Chichester, UK: Wiley, 2006.

35. R.G. Brereton. "Chemometrics for Pattern Recognition". Chichester, U.K: Wiley 2009.

36. K. Danzer, H. Hobert, C. Fischbacher, K.-U. Jagemann, (eds.). "Chemometrik: Grundlagen und Anwendungen". Berlin: Springer, 2001 . 
37. W. Härdle, L. Simar. "Applied Multivariate Statistical Analysis". New York: Springer, Berlin, 2007. 2nd ed.

38. M.J. Adams. "Chemometrics in Analytical Spectroscopy". Cambridge, UK: Royal Society of Chemistry, 2004. 2nd Ed.

39. R.G. Brereton. "Introduction to Multivariate Calibration in Analytical Chemistry". Analyst. 2000. 125(I I): 2125-2154.

40. S.Y. Venyaminov, F.G. Prendergast. "Water $\left(\mathrm{H}_{2} \mathrm{O}\right.$ and $\left.\mathrm{D}_{2} \mathrm{O}\right)$ Molar Absorptivity in the $1000-4000 \mathrm{~cm}^{-1}$ Range and Quantitative Infrared Spectroscopy of Aqueous Solutions". Anal. Biochem. 1997. 248(2): 234-245.

4I. S.J. Hug. "In Situ Fourier Transform Infrared Measurements of Sulfate Adsorption on Hematite in Aqueous Solutions". J. Colloid Interface Sci. 1997. 188(2): 415-422.

42. J. Emsley. "The Elements". Oxford: Clarendon Press; Oxford University Press, 1989. 3rd ed.

43. X. Lefebvre, J. Palmeri, P. David. "Nanofiltration Theory: An Analytic Approach for Single Salts". J. Phys. Chem. B. 2004. 108(43): I68II-16824.

44. R. Mancinelli, A. Botti, F. Bruni, M.A. Ricci, A.K. Soper. "Hydration of Sodium, Potassium, and Chloride lons in Solution and the Concept of Structure Maker/Breaker". J. Phys. Chem. B. 2007. III (48): |3570-13577.

45. H.J. Bakker, M.F. Kropman, A.W. Omta. "Effect of lons on the Structure and Dynamics of Liquid Water". J. Phys. Condens. Matter. 2005. 17(45): S3215-S3224.

46. Y. Marcus. "Effect of lons on the Structure of Water: Structure Making and Breaking". Chem. Rev. 2009. 109(3): 1346-1370.

47. P. D'Angelo, V. Migliorati, L. Guidoni. "Hydration Properties of the Bromide Aqua lon: The Interplay of First Principle and Classical Molecular Dynamics, and X-ray Absorption Spectroscopy". Inorg. Chem. 2010. 49(9): 4224-423I.

48. V. Vchirawongkwin, B.M. Rode, I. Persson. "Structure and Dynamics of Sulfate lon in Aqueous Solution: An ab initio QMCF MD Simulation and Large Angle X-ray Scattering Study". J. Phys. Chem. B. 2007. III(I6): 4I50-4I55.
49. M. Ostra, C. Ubide, M. Vidal, J. Zuriarrain. "Detection Limit Estimator for Multivariate Calibration by an Extension of the IUPAC Recommendations for Univariate Methods". Analyst. 2008. 133(4): 532-539.

50. F. Allegrini, A.C. Olivieri. "IUPAC-Consistent Approach to the Limit of Detection in Partial Least-Squares Calibration". Anal. Chem. 2014. 86(I5): 7858-7866.

5I. G. Onori, A. Santucci. "IR Investigations of Water Structure in Aerosol OT Reverse Micellar Aggregates". J. Phys. Chem. 1993. 97(20): 5430-5434.

52. J.-B. Brubach, A. Mermet, A. Filabozzi, A. Gerschel, D. Lairez, M.P. Krafft, et al. "Dependence of Water Dynamics upon Confinement Size”. J. Phys. Chem. B. 200I. 105(2): 430-435 [AQ4].

53. C. Boissière, J.B. Brubach, A. Mermet, G. de Marzi, C. Bourgaux, E. Prouzet, et al. "Water Confined in Lamellar Structures of AOT Surfactants: An Infrared Investigation". J. Phys. Chem. B. 2002. 106(5): 1032-1035 [AQ5].

54. J.-B. Brubach, A. Mermet, A. Filabozzi, A. Gerschel, P. Roy. "Signatures of the Hydrogen Bonding in the Infrared Bands of Water". J. Chem. Phys. 2005. 122(18): 184509.

55. B. Mizaikoff. "Waveguide-Enhanced Mid-Infrared Chem/Bio Sensors". Chem. Soc. Rev. 2013. 42(22): 8683.

56. X. Wang, M. Karlsson, P. Forsberg, M. Sieger, F. Nikolajeff, L. Österlund, et al. "Diamonds are a Spectroscopist's Best Friend: Thin-Film Diamond Mid-Infrared Waveguides for Advanced Chemical Sensors/Biosensors". Anal. Chem. 2014. 86(I6): 8I36-814I [AQ6].

57. P. Houizot, M.-L. Anne, C. Boussard-Plédel, O. Loréal, H. Tariel, J. Lucas, et al. "Shaping of Looped Miniaturized Chalcogenide Fiber Sensing Heads for Mid-Infrared Sensing". Sensors. 2014. 14(10): 17905-179|4 [AQ7].

58. D. Geörg, R. Schalk, F.-J. Methner, T. Beuermann. "MIR-ATR Sensor for Process Monitoring”. Meas. Sci. Technol. 2015. 26(6): 06550I.

59. D. Li, Y. Sun, S. Yu, C. Sun, H. Yu, K. Xu. "A Single-Loop Fiber Attenuated Total Reflection Sensor Enhanced by Silver Nanoparticles for Continuous Glucose Monitoring”. Sens. Actuators B. 2015. 220: 1033-1042. 